Check for updates

Cite this: RSC Adv., 2017, 7, 50420

\title{
Strategy for the detection of mercury ions by using exonuclease III-aided target recycling
}

\author{
Minhao Xie, (D) * Kai Zhang, (D) Feifan Zhu, (D) Hao Wu (D) and Pei Zou (D)
}

Herein, a simple, highly sensitive and selective exonuclease III (Exo III)-based sensor was developed for mercury ions $\mathrm{Hg}^{2+}$ detection without the need of complicated, high-cost and time-consuming labeling. In this strategy, two oligonucleotides were employed for the experiment design. DNA1 was prepared with one DNA strand which was designed as a quadruplex-forming oligomer, and which was constructed as $3^{\prime}$-protruding to ensure the probe cannot be digested by Exo III. When the target $\mathrm{Hg}^{2+}$ is introduced into the sensing system, it associates with DNA1 and DNA2 to form double strand DNAs (DNA1/DNA2 duplexes) which have a blunt 3 '-terminus. Exo III then can degrade part of DNA1, releasing the DNA1 and $\mathrm{Hg}^{2+}$, and ultimately liberating the G-rich oligomer. This released G-rich oligomer folds into a G-quadruplex structure and thus allows the formation of DNAzyme in the presence of hemin. The formed DNAzyme can effectively catalyze the $\mathrm{H}_{2} \mathrm{O}_{2}$-mediated oxidation of ABTS, giving rise to a change in solution color. The released DNA1 and $\mathrm{Hg}^{2+}$ are free to bind to another $3^{\prime}$-protruding terminus of DNA1 to trigger a new digestion reaction, leading to significant amplification of the signal. The present new strategy shows a limit of detection as low as $66 \mathrm{pM}$ and excellent selectivity toward $\mathrm{Hg}^{2+}$ over a wide range of metal ions.

Received 22nd August 2017

Accepted 25th October 2017

DOI: $10.1039 / \mathrm{c} 7 \mathrm{ra09288a}$

rsc.li/rsc-advances residues to form a $\mathrm{T}-\mathrm{Hg}-\mathrm{T}$ base pair. The $\mathrm{Hg}^{2+}$-mediated $\mathrm{T}-\mathrm{Hg}^{2+}-\mathrm{T}$ pair is even more stable than the Watson-Crick A-T pair, without affecting the double-helical structure. ${ }^{4}$ Because of this property, many DNA sensors for $\mathrm{Hg}^{2+}$ detection based on fluorescence, colorimetry, electrochemistry, and resonance scattering have been constructed by rational design of DNA sequences. $^{4-8}$

To realize ultrasensitive detection of these trace amounts of $\mathrm{Hg}^{2+}$, effective signal amplifications are commonly required. In recent years, the polymerase chain reaction (PCR)-like amplification strategies, including isothermal exponential amplification reaction (EXPAR), rolling circle amplification (RCA) ${ }^{9}$ and ligase chain reaction, ${ }^{\mathbf{1 0}}$ have been incorporated into the biosensor strategy to achieve highly sensitive detection of targets. Although high sensitivity can be obtained by these PCRlike amplification strategies, these sensing strategies are limited due to the drawbacks of complex handing operation, easy contamination and longtime reaction. ${ }^{11-13}$ On the other hand, a new class of signal amplification strategies based on nuclease (exonuclease or endonuclease)-assisted target recycling has been reported. The nuclease with sequence specific activity can degrade the specific probe to release the target DNA strands to achieve target recycling amplification. ${ }^{\mathbf{1 4 - 1 8}}$ This signal amplification strategy has been demonstrated to be useful in detection trace levels of proteins molecules or DNA targets. Unlike endonuclease which requires specific sequences for recognition, exonuclease has received increasing interest in target recycling-amplified DNA detection. For example,
Key Laboratory of Nuclear Medicine, Ministry of Health, Jiangsu Key Laboratory of Molecular Nuclear Medicine, Jiangsu Institute of Nuclear Medicine, Wuxi, Jiangsu 214063, China.E-mail:xieminhaoi@jsinm.org 
exonuclease III (Exo III), which catalyzed the stepwise removal of mononucleotides from 3 -termini, has been successfully used for amplifying detection of DNA targets ${ }^{\mathbf{1 3 , 1 5 , 1 9 , 2 0}}$ small molecules and proteins. ${ }^{21,22}$ Despite the wide application of the nucleaseassisted recycling amplification in sensitive target detection, the extension of this technique for metal detection remains a major challenge because Exo III shows activity only on dsDNA strands.

Herein, a simple, highly sensitive and selective Exo III-based fluorescent sensor has been developed for $\mathrm{Hg}^{2+}$ detection without the need of complicated, high-cost and timeconsuming labeling. Also, this method can be devised utilizing both the advantages of label-free architectures and signal-on architectures.

\section{Experimental}

\section{Materials and chemicals}

Oligonucleotides (guaranteed oligos, HPLC-purified) were purchased from Genscript Co., Ltd. (Nanjing, China). The sequence of the probe is as follows: DNA1: $5^{\prime}$ TTTGGGTAGGGCGGGTTGGGTACCCAAAATTCTTTCTT-3'; DNA2: 5'-TTGTTTGTTT-3'. Deionized (D. I.) water produced by a Milli-Q Millipore system (18.2 M $\mathrm{cm}$, Millipore Corp., Billerica, MA) was used for the preparation of all the solutions. ABTS (2,2-azinobis (3-ethylbenzothiazoline)-6-sulfonic acid), hemin, $\mathrm{H}_{2} \mathrm{O}_{2}$, and HEPES (4-(2-hy-droxyethyl) piperazine-1-ethanesulfonic acid sodium salt) were purchased from Aladdin Reagents (Shanghai, China) and used as supplied. All other chemicals and solvents were obtained from the commercial sources and used directly without any further purification. Hemin stock solution (1 $\mathrm{mM})$ was prepared in dimethylsulfoxide (DMSO) and stored at $-20{ }^{\circ} \mathrm{C}$. ABTS $^{2-}$ and $\mathrm{H}_{2} \mathrm{O}_{2}$ solution were freshly prepared before used.

\section{Amplification reaction}

Firstly, the mixture of DNA1 $(2 \mu \mathrm{M}, 10 \mu \mathrm{L})$, DNA2 $(2 \mu \mathrm{M}, 10 \mu \mathrm{L})$ and different concentration $(0,300,500,700,800,1000,1500$, 3000 , and $5000 \mathrm{pM}$ ) of $\mathrm{Hg}^{2+}$ in $10 \mathrm{mM}$ phosphate buffer solution (PBS, 0.1 M NaCl, pH 7.4) in a microtest tube incubated in room temperature for about $20 \mathrm{~min}$ to form the stem-loop structure DNA. Subsequently, the solution was incubated with $30 \mu \mathrm{L}$ of 10 $\times$ NEBuffer solution containing $20 \mathrm{U}$ Exo III at $37^{\circ} \mathrm{C}$ for $20 \mathrm{~min}$. Finally, the resulting mixtures were heated at $90{ }^{\circ} \mathrm{C}$ for $10 \mathrm{~min}$ to deactivate the Exo III. For control experiment, the $\mathrm{Pb}^{2+}, \mathrm{Cu}^{2+}$, $\mathrm{Cd}^{2+}$, and $\mathrm{Zn}^{2+}$ were used.

\section{Gel electrophoresis}

Denaturing polyacrylamide gel electrophoresis (PAGE) (20\%) was carried out in $1 \times$ TBE buffer at a $100 \mathrm{~V}$ constant voltage for $1 \mathrm{~h}$. The mixture of DNA1, DNA2 and $\mathrm{Hg}^{2+}$ was incubated in Exo III solution ( $20 \mathrm{U})$ at $37{ }^{\circ} \mathrm{C}$ for $1 \mathrm{~h}$. Afterword, digestions were stopped by heating at $90{ }^{\circ} \mathrm{C}$ for $20 \mathrm{~min}$. Then, the resulting mixtures were heated at $90{ }^{\circ} \mathrm{C}$ for $10 \mathrm{~min}$ to deactivate the Exo III. The gel was taken photograph under UV light after staining with EtBr for $15 \mathrm{~min}$. The concentration of each DNA is $1 \mu \mathrm{M}$.

\section{Colorimetric measurement}

The above mentioned solutions were moved to 96-well microtiter plates. $4 \mu \mathrm{L}$ of hemin $(10 \mu \mathrm{M})$ and $126 \mu \mathrm{L}$ of HEPES buffer (25 mM HEPES, $20 \mathrm{mM} \mathrm{KCl,} 200 \mathrm{mM} \mathrm{NaCl}, 0.05 \%$ Triton X-100, and $1 \%$ DMSO, pH 7.4) were then added, and the mixture was incubated for $60 \mathrm{~min}$ at room temperature. $\mathrm{ABTS}^{2-}$ and $\mathrm{H}_{2} \mathrm{O}_{2}$ (20 $\mu \mathrm{L}$ in total) were added to the mixture to reach final concentrations of $6 \mathrm{mM}$ and $2 \mathrm{mM}$, respectively. Absorption intensity of the solutions were taken after $5 \mathrm{~min}$ of color development.

\section{Instrumentation}

The absorption intensities were recorded by a SpectraMax M5 Multi-Mode Microplate Readers (Molecular Devices, USA), using a Costar 96 well microtiter plate (No. 3599, Corning, New York, USA).

\section{Results and discussion}

\section{Mechanism of this strategy}

The working principle of the designed Exo III amplification and DNAzyme canalization based colorimetric biosensor is illustrated in Scheme 1. The system mainly consists of DNA1 and DNA2. DNA1 includes three domains: the classical G-rich sequence which can form a G-quadruplex in the presence of hemin and $\mathrm{K}^{+}$, the sequence that is complementary to part of Grich sequence and the sequence that is complementary to DNA2 at the help of $\mathrm{Hg}^{2+}$.

DNA1 was prepared with one DNA strand which designed as a quadruplex-forming oligomer, and which was constructed as 3 -protruding to ensure the probe cannot be digested by Exo III since Exo III only cleaves dsDNA strands with blunt of $3^{\prime}$ recessing termini. However, when the target $\mathrm{Hg}^{2+}$ is introduced into the sensing system, it associates with DNA1 and DNA2 to form double strand DNAs (DNA1/DNA2 duplexes) which have a blunt 3 -terminus. Exo III then can degrade part of DNA1, releasing the DNA1 and $\mathrm{Hg}^{2+}$, and ultimately liberating the Grich oligomer. This released G-rich oligomer folds into a Gquadruplex structure and thus allows the formation of DNAzyme in the presence of hemin. The formed DNAzyme can effectively catalyze the $\mathrm{H}_{2} \mathrm{O}_{2}$-mediated oxidation of ABTS $\left(\lambda_{\max }=418 \mathrm{~nm}\right)$, giving rise to a change in solution color. The

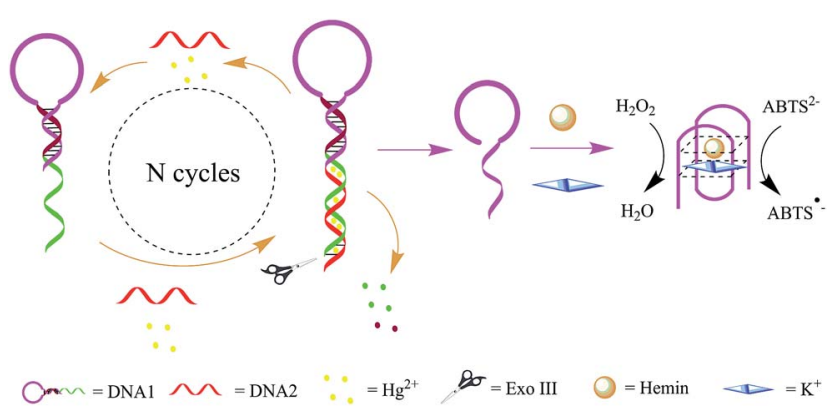

Scheme 1 Schematic illustration of the Exo III and G-quadruplexbased strategy for the detection of $\mathrm{Hg}^{2+}$. 
released DNA1 and $\mathrm{Hg}^{2+}$ are free to bind to another $3^{\prime}$ protruding terminus of DNA1 to trigger a new digestion reaction, leading to significant amplification of the signal.

\section{Feasibility study}

To verify the feasibility of quantitative detection, the UV-vis absorption intensity changes under different conditions were investigated. As shown in Fig. 1, the absorption of the mixture of DNA1 and DNA2 (curve a), and the mixture of DNA1 and DNA2 with $\mathrm{Hg}^{2+}$ (3000 pM) (curve b) was relatively low. Upon addition of Exo III to the DNA1/DNA2 mixture without $\mathrm{Hg}^{2+}$, the absorption intensity increase was only $10.9 \%$ (curve c).

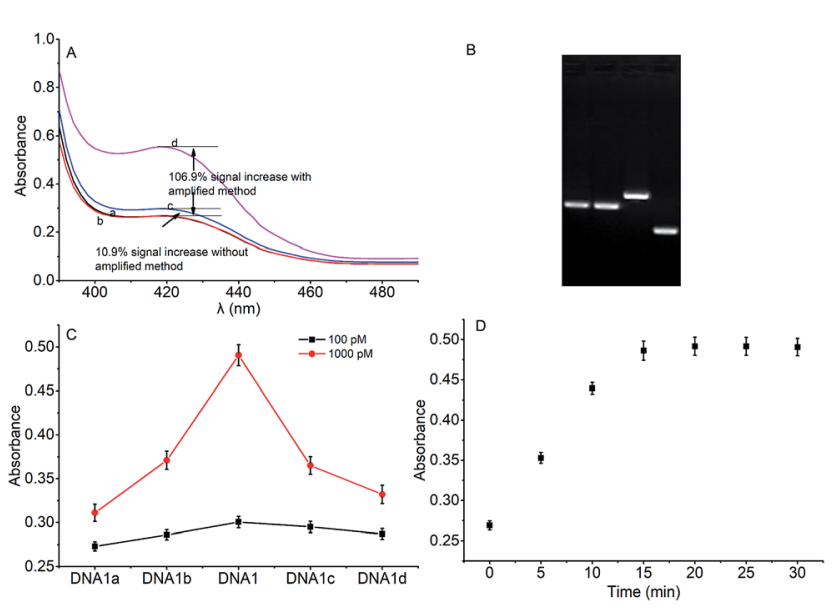

Fig. 1 (A) The UV-vis absorption intensity under different conditions: (a) DNA1 and DNA2; (b) DNA1, DNA2 and $3000 \mathrm{pM} \mathrm{Hg}^{2+}$; (c) DNA1 and DNA2 with Exo III; (d) DNA1, DNA2 and 3000 pM Hg${ }^{2+}$ with Exo III. (B) Denaturing polyacrylamide gel electrophoresis characterization of the products by the Exo III assisted amplification method. Lanes (1) DNA1, (2) DNA1 and DNA2, (3) DNA1- $\mathrm{Hg}^{2+}-\mathrm{DNA} 2$ complex, and (4) DNA1, DNA2 and $\mathrm{Hg}^{2+}$ incubated with Exo III. Products (a) to (c): (a) DNA1; (b) DNA1- $\mathrm{Hg}^{2+}$-DNA2 complex; and (c) G-rich oligomer. DNA2 hard to be distinguished in the gel since the sort length (10 bp). (C) The absorption intensity difference of the method fabricated by five T-rich DNA sequences for the detection of $\mathrm{Hg}^{2+}$ at $100 \mathrm{pM}$ (black points) and 1000 pM (red points), respectively. (D) Optimization of the incubation time of $\mathrm{Hg}^{2+}$
However, when both $\mathrm{Hg}^{2+}(3000 \mathrm{pM})$ and Exo III were present in the solution, we observed $106.9 \%$ increase in the absorption intensity (curve d). The amplification reactions were further verified by using denaturing polyacrylamide gel electrophoresis (PAGE), and the results showed that $\mathrm{Hg}^{2+}$ and Exo III can start amplification reaction and produce G-rich oligomer (line 1, product c).

\section{Optimization of conditions}

According to the proposed $\mathrm{Hg}^{2+}$ assay mechanism, the number of the T-T mismatch base pairs should be carefully selected. To meet this requirement and select the best sequence, five versions of T-rich DNA were designed for test (Table 1). The DNAs were used to fabricate the amplification system with the same method and under the same condition. In order to obtain the highest sensitivity of the sensor, current changes of the five T-rich DNAs for $100 \mathrm{pM}$ and $1000 \mathrm{pM} \mathrm{Hg}^{2+}$ were used for comparison. As shown in Fig. 1C, the results demonstrated that the DNA1 had the highest absorbance.

Incubation times will affect the formation of the $\mathrm{T}-\mathrm{Hg}^{2+}-\mathrm{T}$ base pairs. The proposed sensor was used for the detection of $1000 \mathrm{pM} \mathrm{Hg}^{2+}$ with different reaction time. As shown in Fig. 1D, the absorbance signals reached the maximum at $15 \mathrm{~min}$, suggesting that the reaction of DNA and $\mathrm{Hg}^{2+}$ have finished. But in consideration of the influence of the $\mathrm{Hg}^{2+}$-DNA reaction, 20 min was finally selected as the reaction time.

\section{Sensitivity and selectivity of the $\mathrm{Hg}^{2+}$ sensing system}

To assess the sensitivity of the strategy, the detection of $\mathrm{Hg}^{2+}$ based on Exo III amplification was tested. In the absence of $\mathrm{Hg}^{2+}$, the DNA1 existed in a duplex structure, upon addition of hemin, the colorimetric signal of such a mixture was very weak due to the weak interaction between the G-rich sequence and hemin. Upon the addition of $\mathrm{Hg}^{2+}$ which was combined with the DNA1 and DNA2, triggering Exo III assisted amplification reaction and releasing the G-rich oligomer to fold into quadruplex structure. Thus, the colorimetric signal was turned "on". As shown in Fig. 2A, the colorimetric signal intensity increased when the concentration of $\mathrm{Hg}^{2+}$ was raised from 0 to $5000 \mathrm{pM}$,

Table 1 The designed DNA sequence

Define

name

Sequence

DNA1

DNA2

DNA1a

DNA2a

DNA1b

DNA2b

DNA1c

DNA2c

DNA1d

DNA2d

\author{
$5^{\prime}$-TTTGGGTAGGGCGGGTTGGGTACCCAAA ATTCTTTCTT - $-3^{\prime}$ \\ $5^{\prime}$ - TTGTTTGTTT $-3^{\prime}$ \\ $5^{\prime}$-TTTGGGTAGGGCGGGTTGGGTACCCAAA ATTCTTTC $-3^{\prime}$ \\ $5^{\prime}$ - GTTTGTTT $-3^{\prime}$ \\ $5^{\prime}$-TTTGGGTAGGGCGGGTTGGGTACCCAAA ATTCTTTCT $-3^{\prime}$ \\ $5^{\prime}$ - TGTTTGTTT $-3^{\prime}$ \\ $5^{\prime}$-TTTGGGTAGGGCGGGTTGGGTACCCAAA ATTCTTTCTTT $-3^{\prime}$ \\ $5^{\prime}$ - TTTGTTTGTTT $-3^{\prime}$ \\ $5^{\prime}$-TTTGGGTAGGGCGGGTTGGGTACCCAAA ATTCTTTCTTTT $-3^{\prime}$ \\ $5^{\prime}$ -
}



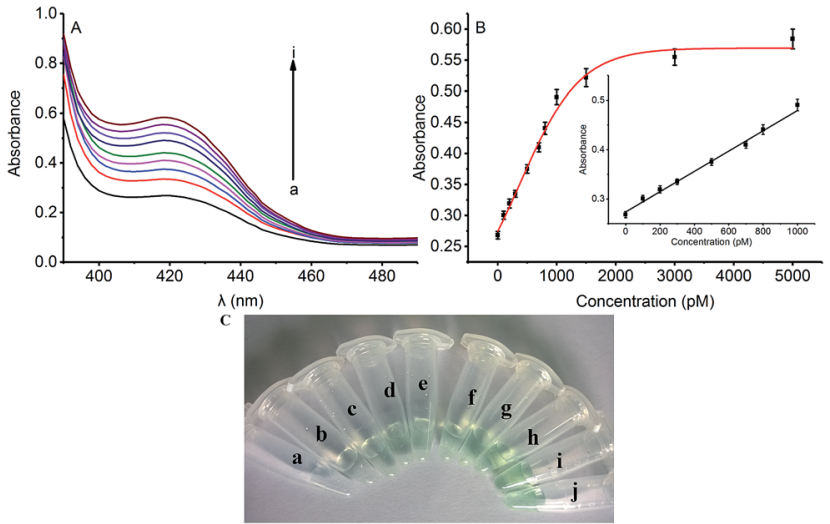

Fig. 2 (A) The UV-vis absorption intensity of the strategy for the assay of $\mathrm{Hg}^{2+}$ at different concentrations: from (a) to (i): 0, 300, 500, 700, $800,1000,1500,3000$, and $5000 \mathrm{pM} \mathrm{Hg}^{2+}$, respectively. (B) The relationship between the absorption intensity and the concentrations of the $\mathrm{Hg}^{2+}$. The insert is shown with the linear range from 0 to 1000 pM. All the data are taken from independent experiments with repetition for at least three times, and the presented data are the results of averaging. (c) Colorimetric analysis by naked eye with different concentrations $\mathrm{Hg}^{2+}$ : from (a) to (j): 0, 300, 500, 700, 800, 1000, 1500, 2000,3000 , and $5000 \mathrm{pM}$.

indicating that the release of the quadruplex-forming oligomer is highly dependent on the concentration of $\mathrm{Hg}^{2+}$. Fig. 2B shows the corresponding calibration plot of the concentration of $\mathrm{Hg}^{2+}$ versus the UV-vis absorption intensity, in which the detection limit was calculated to be $66 \mathrm{pM}$ according to the responses of the blank tests plus 3 times the standard deviation $(3 \sigma)$. A good linear range from 0 to $1000 \mathrm{pM}$ was shown in the insert of Fig. 2B. The fitting equation of the curve shown in the insert of Fig. $2 \mathrm{~B}$ is $Y=0.00021 X+0.274\left(R^{2}=0.991\right)$, where $Y$ is the absorption intensity and $X$ is the concentration of $\mathrm{Hg}^{2+}$. Such low detection limit ( $66 \mathrm{pM}$ ) for $\mathrm{Hg}^{2+}$ detection is even lower to some existing signal amplification methods that using amplification strategy ${ }^{\mathbf{1 4}}$ and nearly 2 orders of magnitude lower to other previously reported $\mathrm{Hg}^{2+}$ detection systems based on catalytic DNAzyme. ${ }^{23}$

The color change in the presence of various concentrations of $\mathrm{Hg}^{2+}$ was also monitored by the naked eye (colorimetric analysis) to achieve visual detection. As illustrated in Fig. 2C, the green color of the reaction solution was gradually intensified with elevated concentration of $\mathrm{Hg}^{2+}$ from 0 to $5000 \mathrm{pM}$. Also, $500 \mathrm{pM}$ (tube c) $\mathrm{Hg}^{2+}$ can be easily identified by the naked eye according to the distinct color difference between the sample and the blank test.

The selectivity of the proposed method is examined by monitoring the colorimetric signal of the solution with the presence of $\mathrm{Hg}^{2+}$ against other metal ions, $\mathrm{Pb}^{2+}, \mathrm{Cu}^{2+}, \mathrm{Cd}^{2+}$, and $\mathrm{Zn}^{2+}$. As shown in Fig. 3, the presence of the control molecules (1000 pM) causes insignificant colorimetric signal change of the solutions while the addition of the target $\mathrm{Hg}^{2+}(1000 \mathrm{pM})$ results in a high colorimetric signal of the probe solution, revealing that the amplification method is highly selective. Such high selectivity can be related to the highly specific binding capability of the $\mathrm{T}-\mathrm{Hg}^{2+}-\mathrm{T}$. In other words, only the presence of $\mathrm{Hg}^{2+}$

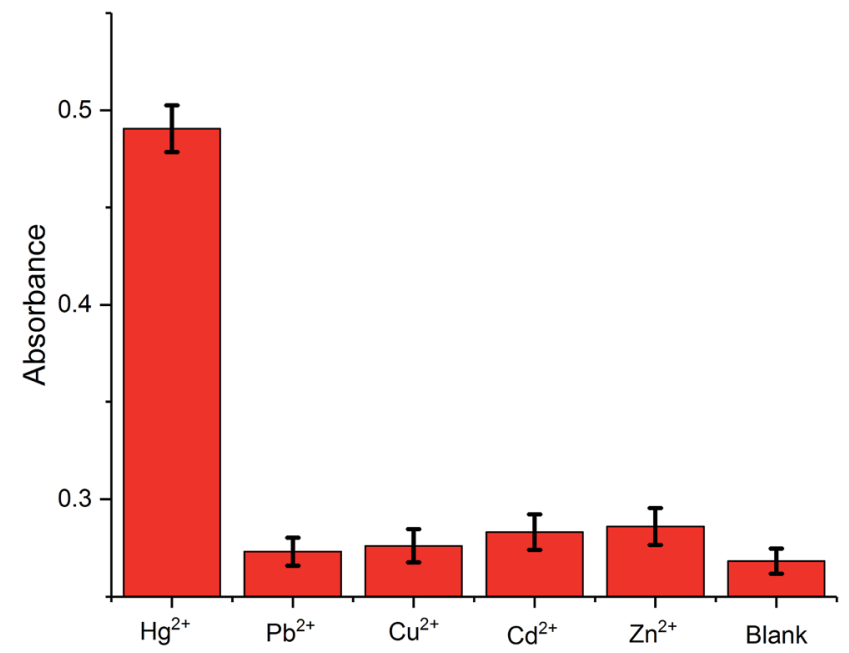

Fig. 3 Selectivity tests of this assay. The concentration of the ions is all $1000 \mathrm{pM}$.

Table 2 Results of the recovery test of $\mathrm{Hg}^{2+}$ in river water

\begin{tabular}{llcl}
\hline Samples & $\mathrm{Hg}^{2+}$ added $(\mathrm{pM})$ & Found $(\mathrm{pM})$ & Recovery $(\%)$ \\
\hline 1 & 200 & 197.6 & $98.8 \pm 2.6$ \\
2 & 500 & 492.3 & $98.5 \pm 2.3$ \\
3 & 1000 & 986.7 & $98.7 \pm 3.2$ \\
4 & 3000 & 2983.9 & $99.5 \pm 1.8$ \\
\hline
\end{tabular}

can trigger amplification cycles to achieve highly visual detection of target.

\section{The real applicability evaluation}

It is critically important to evaluate the real applicability of the amplification method by challenging this strategy in various media. Given that the strategy is resistant to other ions influence, we challenged the assay by analyzing samples of complicated matrix to evaluate the applicability of the strategy to river water. Four concentration of $\mathrm{Hg}^{2+}$ (200 pM, 500 pM, $1000 \mathrm{pM}$, $3000 \mathrm{pM}$ ) were spiked into river water. Table 2 is shows the experimental results obtained in $\mathrm{Hg}^{2+}$-spiked river water samples. $\mathrm{Hg}^{2+}$ concentration recoveries of $98.5-99.5 \%$ were achieved. These results showed that the interference of river water could be overcome. It means that, our proposed strategy could potentially be applied to realistic river water samples.

\section{Conclusions}

In summary, we have developed a novel highly sensitive method to quantify $\mathrm{Hg}^{2+}$ as low as $66 \mathrm{pM}$ by integrating a recycling cycles and demonstrated its feasibility in the application of realistic detection. We suggest that this assay offers two advantages. First, the assay does not involve any chemical modification of DNA, which makes it simple, low-cost and makes it a label-free strategy. Second, the method does not require troublesome separation procedures. We believe that, this method has the 
potential to be used as a major tool for ultrasensitive quantitative analysis of $\mathrm{Hg}^{2+}$ or other heavy metal ions in river water.

\section{Conflicts of interest}

There are no conflicts to declare.

\section{Acknowledgements}

We acknowledge financial support by the Social Development Foundation of Jiangsu (grant No. BE2013614)

\section{Notes and references}

1 J. Huang, X. Gao, J. Jia, J.-K. Kim and Z. Li, Anal. Chem., 2014, 86, 3209-3215.

2 X. Liu, Y. Tang, L. Wang, J. Zhang, S. Song, C. Fan and S. Wang, Adv. Mater., 2007, 19, 1662.

3 S. He, D. Li, C. Zhu, S. Song, L. Wang, Y. Long and C. Fan, Chem. Commun., 2008, 4885-4887, DOI: 10.1039/b811528a.

4 S.-J. Liu, H.-G. Nie, J.-H. Jiang, G.-L. Shen and R.-Q. Yu, Anal. Chem., 2009, 81, 5724-5730.

5 Z. Zhu, Y. Su, J. Li, D. Li, J. Zhang, S. Song, Y. Zhao, G. Li and C. Fan, Anal. Chem., 2009, 81, 7660-7666.

6 X. Liu, A. Gao, T. Li, P. Zhou, Y. Wang, Q. Yang, L. Wang and C. Fan, in 2010 Ieee Sensors, Ieee, 2010, pp. 1971-1974, DOI: 10.1109/icsens.2010.5689894.

7 Y. Helwa, N. Dave, R. Froidevaux, A. Samadi and J. Liu, ACS Appl. Mater. Interfaces, 2012, 4, 2228-2233.

8 M. Stobiecka, A. A. Molinero, A. Chałupa and M. Hepel, Anal. Chem., 2012, 84, 4970-4978.
9 J. Ge, L.-L. Zhang, S.-J. Liu, R.-Q. Yu and X. Chu, Anal. Chem., 2014, 86, 1808-1815.

10 K. Brückner, K. Schwarz, S. Beck and M. W. Linscheid, Anal. Chem., 2013, 86, 585-591.

11 K. Zhang, K. Wang, X. Zhu, J. Zhang, L. Xu, B. Huang and M. Xie, Chem. Commun., 2014, 50, 180-182.

12 K. Wang, K. Zhang, Z. Lv, X. Zhu, L. Zhu and F. Zhou, Biosens. Bioelectron., 2014, 57, 91-95.

13 S. Bi, L. Li and Y. Cui, Chem. Commun., 2012, 48, 1018-1020.

14 F. Xuan, X. Luo and I. M. Hsing, Anal. Chem., 2013, 85, 45864593.

15 F. Xuan, X. Luo and I. M. Hsing, Anal. Chem., 2012, 84, 52165220.

16 Y. Huang, S. Zhao, Z.-F. Chen, M. Shi, J. Chen and H. Liang, Chem. Commun., 2012, 48, 11877-11879.

17 P. Hu, C. Zhu, L. Jin and S. Dong, Biosens. Bioelectron., 2012, 34, 83-87.

18 Y. Zhang, H. Zhang and N. Hu, Biosens. Bioelectron., 2008, 23, 1077-1082.

19 X. Zuo, F. Xia, Y. Xiao and K. W. Plaxco, J. Am. Chem. Soc., 2010, 132, 1816-1818.

20 S. Bi, X. Jia, J. Ye and Y. Dong, Biosens. Bioelectron., 2015, 71, 427-433.

21 X. Liu, R. Freeman and I. Willner, Chem.-Eur. J., 2012, 18, 2207-2211.

22 S. Bi, B. Luo, J. Ye and Z. Wang, Biosens. Bioelectron., 2014, 62, 208-213.

23 N. Lu, C. Shao and Z. Deng, Analyst, 2009, 134, 1822-1825. 